\title{
The history of Ephedra (ma-huang)
}

\author{
MR Lee \\ Emeritus Professor of Clinical Pharmacology and Therapeutics, University of Edinburgh, Edinburgh, UK
}

\begin{abstract}
Ephedra is a Chinese shrub which has been used in China for medicinal purposes for several thousand years. The pure alkaloid ephedrine was first isolated and characterised by Nagai in 1885. It was then forgotten until it was rediscovered by Chen and Schmidt in the early 1920s. Its actions on the adrenoceptors could be classified into separate alpha and beta effects - a defining moment in the history of autonomic pharmacology. Ephedrine became a highly popular and effective treatment for asthma, particularly because, unlike adrenaline (until then the standard therapy), it can be given by mouth. Ephedrine as a treatment for asthma reached its zenith in the late 1950s, since when there has been a gradual and inevitable decline in its therapeutic use. From mainstream medicine, ephedrine moved into the twilight zone of street drugs and nutritional supplements. Ephedra and ephedrine products are now banned in many countries, as they are a major source for the production of the addictive compound methamphetamine (crystal meth).
\end{abstract}

Correspondence to MR Lee, I/ 2 Polwarth Terrace, Edinburgh EHII INN, UK

tel. +44 (0) I 3 I 3377386

KEYWORDS Adrenaline, Ahlquist, amphetamine, asthma, Ephedra, ephedrine

DECLARATION OF INTERESTS No conflict of interests declared.

\section{EARLY HISTORY}

Ephedra (ma-huang) is a Chinese shrub that has been known for at least 5,000 years. The Chinese emperor Shen Nung, around 2,700 BC, catalogued 365 herbs in terms of their bitterness, the main groups being strong, medium and mild. Ma-huang, whose literal translation means 'hemp yellow', was placed in the medium group.

In the latter part of the sixteenth century, Li Shih-Chen produced a famous dispensatory, the Pents'ao Kang Mu, in which the shrub is clearly described., Ephedra was said to be useful as a circulatory stimulant, a diaphoretic and an antipyretic. It was also believed to be useful in the treatment of cough and as a result the stem became an important ingredient of many antitussive preparations. At the end of the sixteenth century the dried stems were exported to Japan, a trade which was to play an important part in stimulating the interest of Japanese physicians and chemists in the plant some three hundred years later.

Other species of Ephedra (later recognised as $E$. pachyclada and E. intermedia) which were thought to have medicinal value were found in Greece, Russia, India and the Americas. Various religious groups, including Hindus and Parsees, used them in their ceremonies to produce feelings of exhilaration. Ephedra acts as a central nervous excitant as a result of the rapid passage of ephedrine through the blood-brain barrier. This stimulates neurons in the limbic system, which also control part of the hypothalamus (supporting a variety of functions, including emotion). As the preparations used by Indian religious sects also contained ethyl alcohol it is impossible in retrospect to know how much of the ecstatic experience was due to alcohol, how much to ephedrine and how much to the interaction between the two psychostimulants.

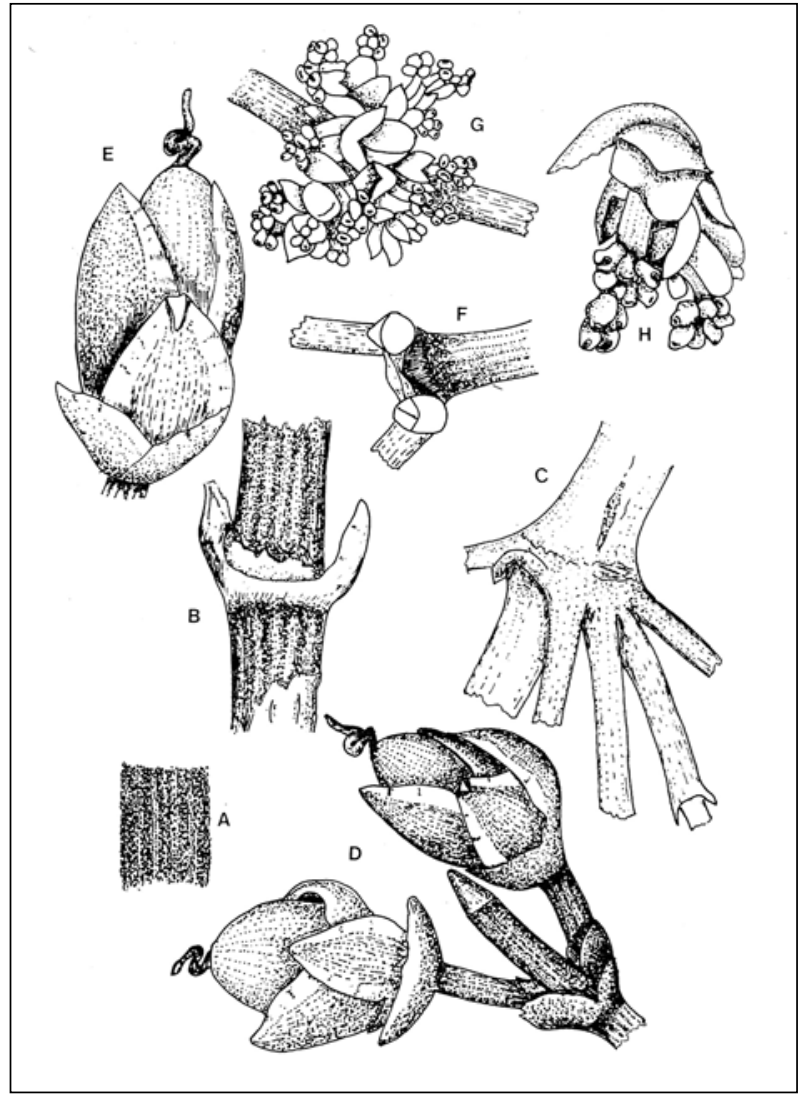

FIGURE I The gymnosperm Ephedra sinica, after drawings by H Riedl. A-E: Female plant. F-H: Male plant. D:Two female cones. (With kind permission of the Royal Botanic Gardens, Edinburgh.)

In the Americas, a number of other Ephedra species were known to the indigenous people. These were later classified as E.antisyphilitica, E. californica and E. nevadensis. ${ }^{3}$ They were thought to act against syphilis and gonorrhoea and were applied either directly to the genital organs or taken by mouth. ${ }^{3} E$. nevadensis had some interesting 
vernacular names such as Mormon tea and whorehouse tea. It seems likely that in the brothel it was thought to stimulate sexual excitement and to protect against sexually transmitted diseases.

To summarise the folk medicine claims up to the 1880 s, it would seem that Ephedra did have some therapeutic action, perhaps in the prevention and treatment of venereal diseases and possibly in the treatment of cough and respiratory complaints.

\section{THE GENUS EPHEDRA}

The Ephedraceae are phylogenetically very old plants belonging to the group of gymnosperms (literally 'naked seeds'), which also includes pines, firs and larches. ${ }^{4}$ There are some 45 species of Ephedra distributed all over the world, particularly in coastal and subalpine areas. They are small shrubs with slender angular and striated branches whose leaves are reduced to membranous scales (Figure I), presumably to reduce transpiration in the arid, windy areas where they survive. The plant is dioecious, that is male and female reproductive organs are carried on different plants. The female apparatus is reduced to an ovule surrounded by red fleshy bracts. At maturity these bracts coalesce to form a structure like a pine cone. In contrast, the male flowers are grouped in yellow tassel-like catkins (Figure I).

The plants vary widely in their production of alkaloids. Some, such as the American and Chilean species, produce hardly any of the active principles. The only common species in Europe is E. distachya, the woody horsetail, which has its habitat on the Atlantic coast and, again, produces little alkaloid. In contrast, the Chinese and Indian species of Ephedra make significant amounts of the active compounds. These species include $E$. sinica and $E$. equisetina in China and $E$. intermedia and $E$. gerardiana in India. The Chinese and Indian species were to become a major commercial source of the ephedrine alkaloids and would in time be shipped all over the world, in particular to the Americas and Europe.

\section{THE DISCOVERY AND ISOLATION OF EPHEDRINE}

Nagayoshi Nagai

Nagayoshi Nagai (1844-1929) is the central figure in the first era of scientific work on ephedrine (Figure 2). ${ }^{5} \mathrm{He}$ studied medicine at the Dutch Academy in Nagasaki and completed his studies in Tokyo. In 1869 the Japanese government lifted the ban on their graduates gaining further training outside the country, while at the same time allowing foreigners to come in for trade and other purposes. Nagai was one of the first to benefit from the relaxation of this law. He travelled to Berlin in 1871 and worked for 12 years with the famous chemist August Wilhelm von Hofmann. He returned to Japan in 1883 and began to work on Ephedra. ${ }^{5}$

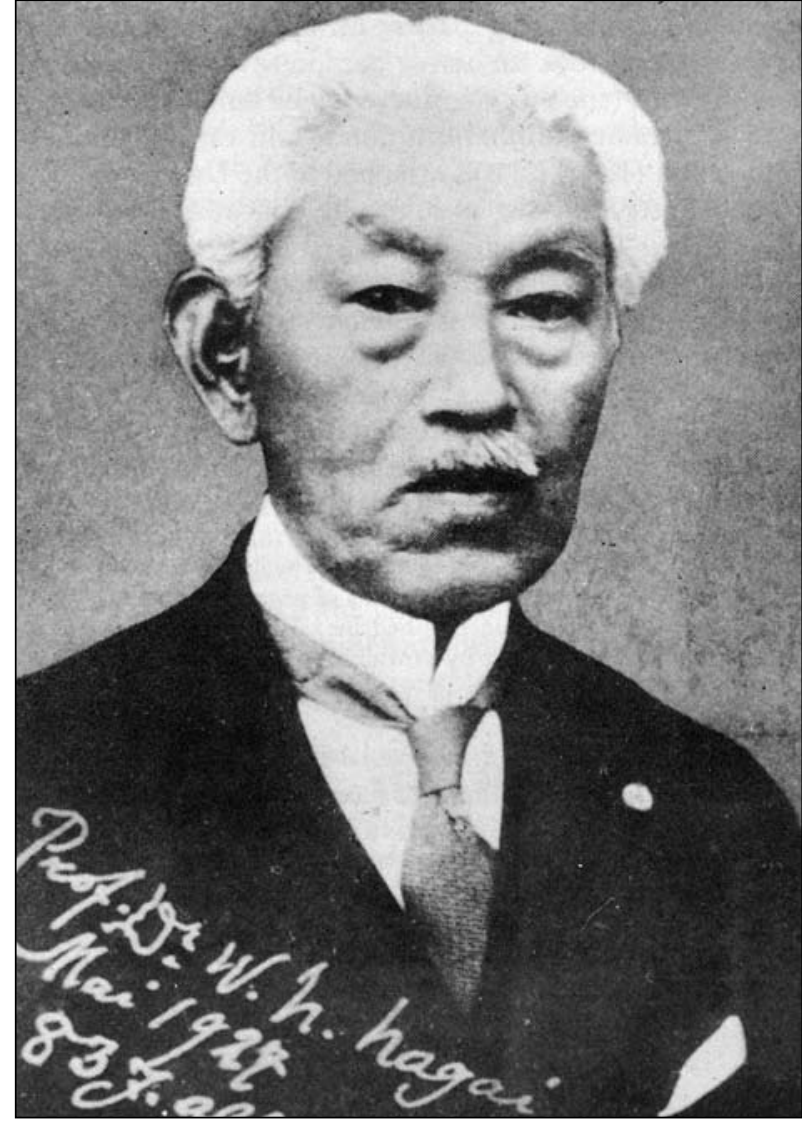

FIGURE 2 Professor Nagayoshi Nagai, the Japanese chemist who discovered and isolated ephedrine for the first time in 1885. (Author's collection.)

In 1885, he isolated ephedrine, which can exist in four forms: I-ephedrine (IR,2S-I-phenyl-2-I-methylaminopropan-I-ol - Figure 3A), which represents $40-90 \%$ of the total alkaloids; d-pseudoephedrine, which has the IS, $2 \mathrm{~S}$ configuration (Figure 3B); and two other minor alkaloids with very little pharmacological activity. ${ }^{6}$ In 1886, the German chemical company E Merck also obtained the pure compound ephedrine. ${ }^{7}$ In the process of isolation the compound l-ephedrine easily racemises to d-ephedrine. This latter compound is relatively inert in pharmacological terms. ${ }^{6}$

Nagai passed his pure preparation of I-ephedrine to his colleague $\mathrm{K}$ Miura who, in 1887 , undertook studies on its pharmacological properties in various animal preparations. ${ }^{8}$ Miura reported that it was too toxic to the circulation to be used in the whole animal (or man), but that it might prove useful as a mydriatic. Its ability to dilate the pupil was readily reversible with time in contrast to the prolonged and possibly dangerous action of the tropane alkaloids, atropine and homatropine. This use of ephedrine as a mydriatic did not gain general acceptance.

There was then a gap of 30 years in which ephedrine remained in limbo, until 1913 when $\mathrm{H}$ Amatsu and $\mathrm{S}$ Kubota, also in Japan, reinvestigated the actions of the 


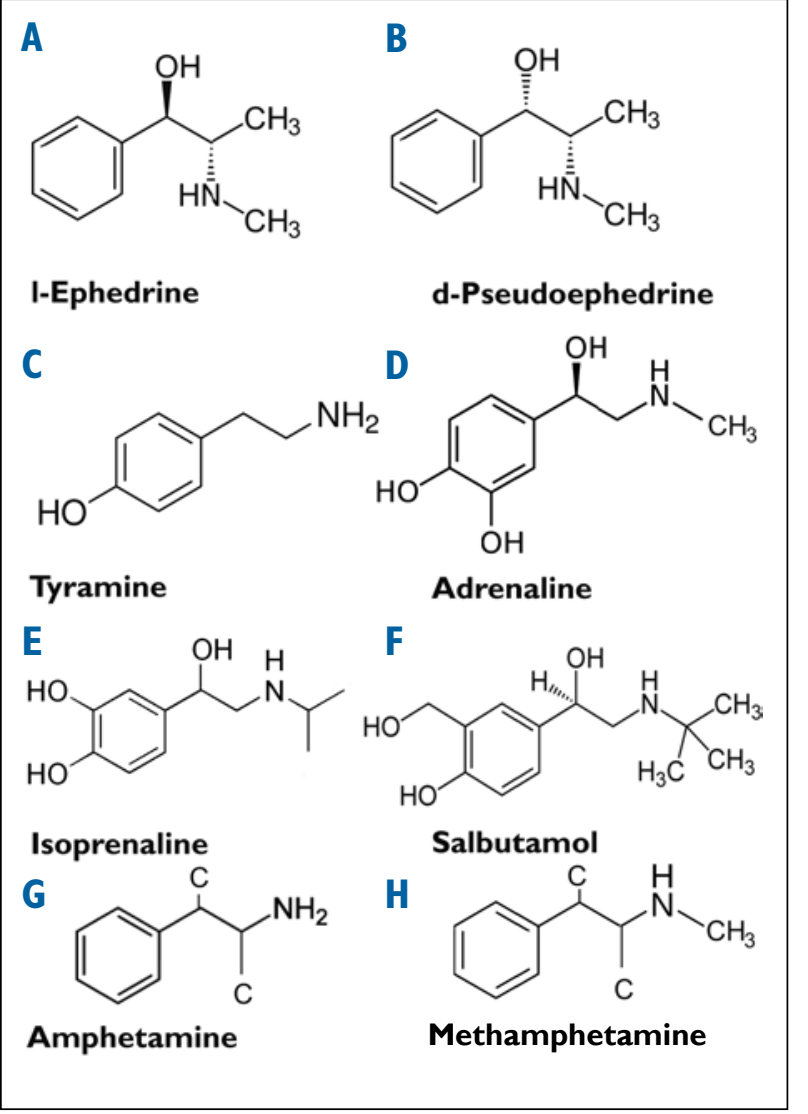

FIGURE 3 The chemical structures of important catecholamines: l-ephedrine (A), d-pseudoephedrine (B), tyramine $(C)$, adrenaline $(D)$, isoprenaline $(E)$, salbutamol $(F)$, and the amine amphetamine $(\mathrm{G})$ and its methyl derivative methamphetamine $(\mathrm{H})$.

alkaloid. ${ }^{9}$ To their surprise, they found that l-ephedrine was a sympathomimetic agent in that it could raise the blood pressure and accelerate the heart. In these actions it resembled tyramine and adrenaline (Figure $3 C$ and D), which had in the intervening years been classified by Barger and Dale as sympathomimetic agents. ${ }^{10}$ Moreover, the Japanese scientists also noticed that ephedrine, like adrenaline, was capable of relaxing bronchial smooth muscle. They therefore suggested that it could have therapeutic potential in the treatment of bronchial asthma. Following this work, an ephedrine-containing medicine was marketed in Mukden (Shenyang), Manchuria, for asthma. It was named Asthmatol, for obvious reasons, but, having little or no success, it fell into disuse.

\section{The rediscovery of ephedrine in 1923}

In the early 1920s, ephedrine was virtually unknown to the Western world. The principal reason for this ignorance was that the original papers from Nagai (and Merck) had been published either in Japanese or German. Proficiency in these languages was limited. When Ko Kuei Chen and Carl F Schmidt took up their posts in 1920 as lecturers at the Peking Union Medical College they decided to investigate promising drugs from the Chinese pharmacopoiea. A local apothecary suggested that ma-huang might be worth another look. Both Chen and Schmidt had been trained in the US and were skilled in new physiological techniques for measuring blood pressure, heart rate and bronchial muscle tone. When they started their work on l-ephedrine they were completely unaware of the previous findings of Nagai and Miura., ${ }^{1,1}$

In their preliminary experiments Chen and Schmidt carried out dose-ranging studies in dogs and cats. The doses of the alkaloid used intravenously were gradually increased from $0.25 \mu \mathrm{g}$ to $10 \mu \mathrm{g}$. The researchers noticed an immediate rise of blood pressure accompanied by an acceleration of the heart, together with a constriction of the peripheral arteries. Other marked effects included the inhibition of intestinal peristalsis, relaxation of bronchial smooth muscle and dilation of the pupils. On analysing the mydriatic response, Chen and Schmidt noticed that although the pupil was dilated, the light reflex was not abolished and the meiotic response to pilocarpine was preserved. They concluded that the parasympathetic innervation to the iris was preserved. Similarly, when the bronchial smooth muscle was contracted by physostigmine (eserine), another parasympathetic stimulant, this effect could be reversed by ephedrine.

Chen and Schmidt came to a number of important conclusions about Ephedra and ephedrine:

- The actions of ephedrine were similar to those of adrenaline and tyramine.

- The actions of ephedrine were more prolonged than those of adrenaline.

- The similarity of the effects of ephedrine to those of adrenaline are reflected in the near-identity of their chemical structures (Figure 3A and 3D).

- Ephedrine properly belongs to the group of 'sympathomimetic amines' (Figure 3 ) as described by Barger and Dale in 1910.10

Chen and Schmidt's paper in the Journal of the Society of Experimental Pharmacology and Therapeutics set the pharmacological world alight." Adrenaline had been isolated and synthesised in the early 1900s and had proven, in the intervening years, to be an effective treatment for asthma. Nevertheless it had substantial drawbacks. For example, it could not be given by mouth as it was rapidly destroyed by enzymes in the gut. Moreover, its results were short-lived and it was not effective in the prevention of asthmatic attacks. If given in repeated doses by injection, in a severe case of bronchospasm, where hypoxia was present, the patient might die suddenly from a ventricular arrhythmia. Finally it was not realised, initially, that adrenaline is inherently unstable. In solution, in the presence of light and/or air, it is rapidly oxidised to inactive substances such as adrenochrome. This was a constant worry when 
physicians blithely carried vials of adrenaline around in their medical bags for months on end. Eventually the problem was solved by the addition of antioxidants such as ascorbic acid.

In all these aspects, ephedrine is superior to adrenaline. It can be given by mouth and the effect is more prolonged than that of adrenaline. As a dry powder or even in solution, it is stable for considerably longer periods than adrenaline. Some patients, in particular children, who could not (or would not) tolerate adrenaline injections could be effectively treated with ephedrine. ${ }^{1,11}$

As a result of their findings Chen and Schmidt decided to send samples of Ephedra and ephedrine to TG Miller, a noted respiratory physician in the US. ${ }^{12}$ Miller was able to show definite bronchodilator effects in asthma, particularly in children, who, as a result, were able to avoid painful injections of adrenaline. ${ }^{2}$ Moreover, ephedrine seemed able to abort severe bronchospasm when given in the prodromal stage of an attack.

The first publications on asthma in the US stimulated what could be called an ephedrine 'gold rush'. Every American paediatrician and respiratory physician wanted to get hold of this 'new' plant or its active alkaloid. This initial enthusiasm lasted from 1924 to 1930. Several patents were filed in the US and Europe for the preparation of the plant extract and for the synthesis of the active alkaloid. Over the same period the tonnage exports of the plant from China to the US rose substantially. One American pharmaceutical company tried to control the market by buying all the supplies of Ephedra in China. This bold attempt failed when supplies of the active extracts of the Indian species of Ephedra became more generally available.'

\section{SUPPLY AND DEMAND: |930-|948}

By the middle of the 1930s ephedrine had become established throughout the Western world as a reliable treatment for asthma. If it failed to alleviate the symptoms, adrenaline given systematically could be administered, which complemented its effect. Primitive inhalers were developed to deliver both drugs, but they proved unsatisfactory as they failed to give a measured dose. This problem would only be solved in the 1960s with a new generation of breath-activated metered-dose inhalers.

Two problems arose in the 1930s. Firstly, Ephedra extracts contained significant amounts of the isomer $\mathrm{d}$-pseudoephedrine. Anxiety arose as to what (if any) contribution pseudoephedrine could make to enhance (or block) the clinical effects of pure l-ephedrine. The second problem arose in 1937 when the Japanese invaded Manchuria in northern China and gradually advanced south. Supplies of Ephedra were in jeopardy and, in fact, shortages did occur. As a result, South

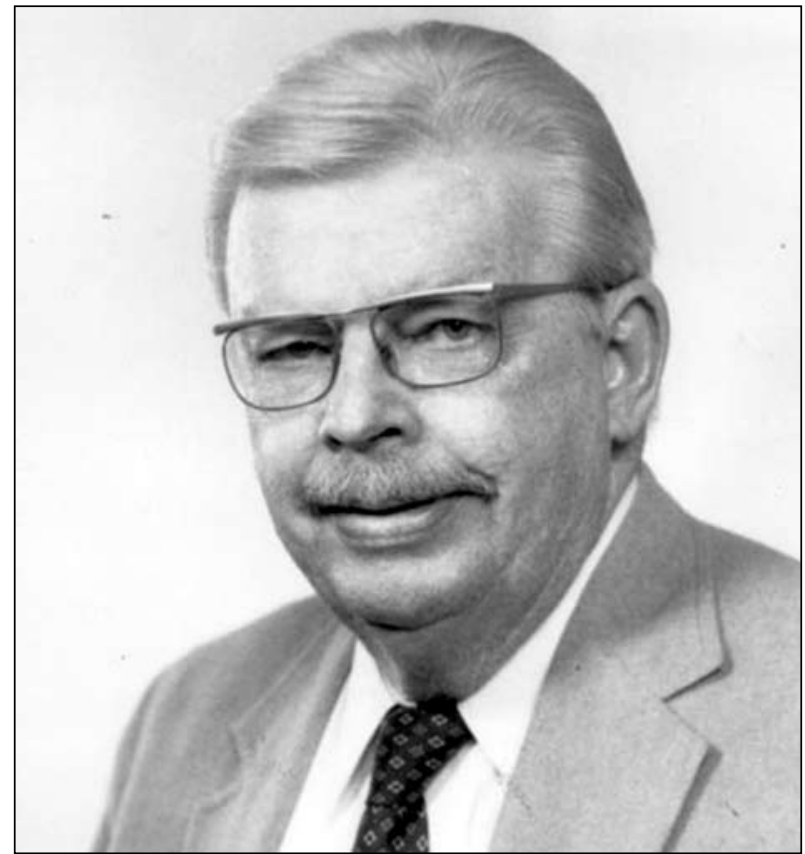

FIGURE 4 Professor Raymond Ahlquist (1914-1983), the American pharmacologist whose study of the actions of ephedrine led to important new discoveries on the classification of adrenoceptors into the alpha and beta types. (With kind permission of the American Society for Pharmacology and Experimental Therapeutics.)

Dakota State College in the US initiated a scheme to grow E. sinica. This attempt was successful and the college supplied specimens to Raymond Ahlquist (Figure 4) for assay.

However, two other developments ensured continued supplies of the drug. India increased the acreage of Ephedra under cultivation and supplies of alkaloid from this area increased. Secondly, a new synthesis for ephedrine was developed. Many methods had been tried previously, but side reactions were common. The new approach was a biological conversion of benzaldehyde by a Saccharomyces yeast to (R)-I-phenyl-I-hydroxy-2propanone. This compound was then converted to ephedrine by methylamine in the presence of an aluminium catalyst. This procedure produces a very large yield of ephedrine in the racemic dl-form, avoiding side reactions. The two isomers can then be separated, producing large amounts of I-ephedrine. ${ }^{6}$ The Ephedra crisis was over; supplies from China and India were no longer needed. (It is interesting to reflect that another serious shortage, that of quinine, could not be solved so easily when the Japanese invasion of Java in 1942 caused a worldwide shortage of this important antimalarial compound.)

\section{Ahlquist and the adrenoreceptor}

Two important developments in the physiology and pharmacology of the autonomic nervous system took place in the 1940s and set the scene for Ahlquist's integrating contribution of $1948 .^{13}$ The first (and most important) was the demonstration by Ulf von Euler at the 
Karolinska Institute in Stockholm, Sweden, that the major neurotransmitter in the sympathetic autonomic nervous system was not, in fact, adrenaline but noradrenaline..$^{14,15}$ This development would change autonomic physiology for ever. The second step forward occurred in 194I when several groups synthesised isoprenaline (isoproterenol) (Figure 3E). This compound would prove to be a powerful bronchodilator and would eventually supersede ephedrine in the treatment of asthma.

Ahlquist then produced a pivotal scientific paper, 'A study of the adrenotropic receptors', in 1948.' ${ }^{13}$ For a number of years he had been working on ephedrine, adrenaline and other catecholamines. He had hoped to produce a more specific ephedrine which would have less activity on the central nervous system. In his paper Ahlquist suggested that there were two distinct types of receptor for adrenaline and the other catecholamines. He named them the alpha-receptor and the beta-receptor respectively. ${ }^{13}$ The alpha-receptor was predominantly excitatory (apart from one inhibitory action on the intestine), whereas the beta-receptor was associated with predominantly inhibitory functions (but had one excitatory effect, that of stimulating the myocardium).

This exciting new concept was first submitted for publication to the Journal of Pharmacology and Experimental Therapeutics, where it was promptly rejected. Ahlquist's friend WF Hamilton, professor of physiology at the University of Georgia School of Medicine in Augusta, Georgia, intervened in the process and managed to get the paper published in the American Journal of Physiology. It has since become a benchmark publication in the history of pharmacology and has had a remarkable 2,285 citations up to January 201 I, according to Google Scholar. Ahlquist did make one significant error in his paper. He assumed that the endogenous adrenergic neurotransmitter was adrenaline (epinephrine). In fact, von Euler had been able to show, in the period from 1946 to 1950, that the endogenous adrenergic transmitter was noradrenaline (norepinephrine), which has predominantly alpha effects..$^{14,15}$

Ahlquist then turned his attention back to ephedrine and examined its effects in terms of his suggested classification of the receptors. He concluded that the plant alkaloid ephedrine had both alpha- and beta-adrenergic agonist effects and the latter was the basis of its therapeutic bronchodilator action. However, ephedrine has two potentially dangerous effects. Firstly, it releases both adrenaline and noradrenaline from the stores in the body and, secondly, it passes the blood-brain barrier with relative ease compared with adrenaline. This relatively easy passage to the brain is due to the extra methyl group in the molecule, which renders it more lipophilic.

\section{DECLINE AND FALL: | 950-20 | |}

Sales of ephedrine peaked in the 1940s and 1950s when it was the main bronchodilator effective by mouth. It was often combined with other bronchodilators such as caffeine or theophylline (the methylxanthines). Common proprietary preparations in the UK were the tablets Amisec and Franol.

\section{Toxicity and addictive properties}

With the widespread use and availability of ephedrine in pure form, or in compound tablets, it gradually became appreciated that the alkaloid was more toxic than had first been supposed. ${ }^{16}$ This was particularly true if it were taken on a long-term preventative basis. The dangers of ephedrine in acute overdose are many and various, but the life-threatening ones affect the central nervous and cardiovascular systems. ${ }^{16}$ Fatalities from overdose are now rare.

When Chen and Schmidt first described the widespread use of ephedrine in clinical medicine in their 1930 monograph, they asserted that they had seen little evidence of withdrawal symptoms when the drug was stopped suddenly.' However, it appears from more modern studies that they were overly optimistic. Individuals can become habituated to the central nervous system effects of ephedrine. As a result, they need to take increasing doses of the alkaloid to produce the same stimulatory effects - as much as I-2 g a day.

Patients taking such large doses of ephedrine often exhibit symptoms of anxiety, restlessness and insomnia. They also can have difficulties in micturition, leading in some cases to urinary retention. Intermittent bouts of paranoid psychosis may occur associated with suicidal (or homicidal) behaviour. ${ }^{17-19}$ A gradual reduction of dose is required together with an administration of oral (or even intravenous) benzodiazepines. These symptoms produced by ephedrine closely resemble those of amphetamine (speed) or methamphetamine (crystal meth), compounds commonly associated with illegal street dealing. On the whole, the symptoms produced by ephedrine withdrawal tend to be less severe and less prolonged than those seen after withdrawal from amphetamines. ${ }^{17-19}$

\section{The search for better bronchodilators}

From 1950, the use of ephedrine began to decline with the emergence of other drug groups, such as the methylxanthines (theophylline) and the corticosteroids (hydrocortisone and prednisolone), which could be used alone or in conjunction with the catecholamine.

The search for better bronchodilators continued and settled at first on the compound isoprenaline ( $\mathrm{N}$-isopropyladrenaline or isoproterenol - Figure 3E). In the early days of the Second World War, Heribert Konzett at Boehringer Ingelheim in Germany recognised 
that this analogue of adrenaline was a promising bronchodilator. ${ }^{20}$ The compound was introduced in 1951 as a rapid treatment for acute asthma when given by inhalation. Unfortunately, it was abused by asthmatics who sometimes took far more than the indicated dose, a practice which led to many thousands of deaths worldwide due to cardiac arrhythmias. In 1967, scientists at Allen \& Hanburys' research division in Ware, Hertfordshire, introduced salbutamol (Figure 3F). ${ }^{21}$ In this compound the hydroxyl group is protected from enzymic destruction by a hydroxymethyl group and a tertiary butyl group reduces salbutamol's affinity for the $\beta_{1}$-receptor in the heart. ${ }^{21,22}$ Salbutamol was a major advance in bronchodilator therapy and, as a result, ephedrine and isoprenaline rapidly became obsolete.

\section{The twilight of ephedrine}

As ephedrine declined as a therapeutic drug in the 1970s and 1980s, crude Ephedra was still being imported into the Americas from China and India. In many South American countries it is still widely available as an over-thecounter medication for coughs, asthma and bronchitis.

Ephedra rapidly gained a reputation as a 'street drug', which soon became as cheap and easily available as cocaine and amphetamine. It was valued in particular as a preparation to give a quick 'high' and was also thought to strengthen muscular performance. Accordingly it began to be used by sportsmen of all types to 'enhance' their performance. If the substance was detected in their urine they could always argue that they had taken the preparation for coryza, pharyngitis or a bronchial condition when in fact they had obtained it from dealers, often in substantial quantities. Perhaps the most famous example of the abuse of an ephedrine/pseudoephedrine mixture (impure Ephedra) was that of the footballer Diego Maradona. ${ }^{23}$ All sportsmen are now tested for the presence in the urine of ephedrine, pseudoephedrine and the metabolite of ephedrine, phenylpropanolamine.

In 2003 a young baseball pitcher from the Baltimore Orioles, Steve Bechler, embarked on a course of a 'nutritional supplement', which was later shown to contain Ephedra. ${ }^{3}$ In the middle of an unpleasantly hot day at training he collapsed, was rushed to hospital and subsequently died. The autopsy revealed that he had suffered hyperthermia complicated by renal and cardiac failure (together with cerebral oedema). A high concentration of ephedrine was detected in the blood. Hyperpyrexia is a known complication of overdose with ephedrine, probably by an action on the hypothalamic thermostat which then acts to prevent general vasodilation and sweating. ${ }^{3,24}$ The sudden death of this fit young man caused a storm of media activity. Anger rose when it turned out that he had taken the toxic plant Ephedra, not knowing that it could be poisonous. When it also transpired that it was perfectly legal to buy the plant as an over-the-counter nutritional supplement, the incident came to be regarded as a national tragedy. In a short time the baseball and athletic authorities banned Ephedra. Somewhat belatedly the Food and Drug Administration reviewed its previous relaxation of the rules and banned all drugs, plant-derived or synthetic, contained in 'nutritional supplements'. The sales of these supplements fell dramatically for several years.

It was then discovered by the Canadian and Mexican authorities that similar deaths had occurred in their legislatures in persons taking Ephedra. The certified causes of death were either cardiac failure, hyperthermia or both. Although we will never know exactly how many people were killed worldwide by Ephedra taken as a nutritional supplement, the figure must run into hundreds. ${ }^{3}$

The sad part of all this is that the tragedy could have been avoided. Since the 1930 study by Chen and Schmidt, it had been shown that ephedrine, in overdose, could produce cardiac failure, hyperthermia, convulsions and death. ${ }^{24}$ The lethal dose for an adult is between I $\mathrm{g}$ and $2 \mathrm{~g}{ }^{24}$

\section{Ephedrine and methamphetamine}

In the past two decades, a final twist has emerged in the long saga of Ephedra and ephedrine. The drug has recently been used in the illicit manufacture of the powerful stimulant methamphetamine (crystal meth). ${ }^{25}$ Methamphetamine can be synthesised in a simple onestep procedure by a chemical reduction of ephedrine or pseudoephedrine (Figure $3 \mathrm{G}$ and $3 \mathrm{H}$ ). The ingredients are widely available in the Americas, over the counter, as imports of the Ephedra plant from China and India. This has led to the growth of two sorts of laboratory in Canada, Mexico and the US: small 'mom and pop' laboratories and large criminal 'super labs', often located in Mexico and the west coast of the US.

These factors have led to an 'epidemic' of addiction to crystal meth in certain regions of the US and Canada, which has resulted in many cases of acute psychosis together with extensive damage to the nervous system. In addition, large numbers of people have been admitted to hospital with burns sustained in making crystal meth in a confined space. ${ }^{25}$

Unlike cocaine, methamphetamine does not have to be transported long distances from Bolivia and Columbia to the US.This makes interdiction difficult or impossible, particularly in the case of the 'mom and pop' laboratories. The situation is reminiscent of the 'moonshine' stills in the days of alcohol prohibition. Moreover, the price of crystal meth on the street is now cheaper than that of cocaine and it is very easily available.

The governments of the US and Mexico are trying to choke off the supplies of Ephedra from Asia but so far with limited success. They are also trying to ban pharmacies from selling ephedrine and pseudoephedrine over the 
counter, but again this has proved to be very difficult, particularly in Latin America. Ephedra, once used as the drug of choice for the treatment of asthma in the 1930s and 1940s, is now helping to fuel the fire of yet another major outbreak of drug addiction in North America.

\section{THE FINAL VERDICT}

In the British National Formulary of March 2010, ephedrine still appears, but almost as an afterthought. It still has its uses as a mydriatic (in eye drops) and as a nasal decongestant, (again in the form of drops). However, its use as an oral drug for asthma has all but disappeared in the UK, supplanted by inhalers containing either salbutamol, salmeterol, ipratropium or steroids. This is a profound change from the 1930s when thousands of tonnes of Ephedra were shipped from Asia to the Americas.

The important contribution that ephedrine made to pharmacology was the development of the theory of alpha- and beta-adrenegic receptors elaborated by Ahlquist while working on the alkaloid. His seminal paper set the scene for the later subdivision of the alpha receptors into $\alpha_{1}$ and $\alpha_{2}$ and the beta receptors into $\beta_{1}$ and $\beta_{2}$, respectively. This discovery has had a profound effect on the whole development of modern pharmacology and therapeutics.
The other process that the discovery of ephedrine illustrates so very well is the theme lying behind all the articles in this series. First, the plant known in folklore is clearly identified, then it is named in the Linnaean binomial system and finally the active substance is isolated and synthesised. Further work will then confirm its pharmacological and therapeutic activity, together with its toxic risk. With ephedrine the first part of this process in China and Japan took from 2,700 BC to the end of the nineteenth century; the final stage from Nagai to Chen and Schmidt a mere 45 years. This compressed period of less than half a century illustrates the power of modern chemical isolation and synthesis.

To conclude, Ephedra and ephedrine deserve an honoured place in the history of pharmacology and therapeutics. To paraphrase the ancient Roman poet Horace, the abuse of a substance does not weigh against its right or proper use.

Acknowledgements I would like to thank lain Milne and Estela Dukan of the RCPE's Sibbald Library; Jane Hutcheon of the Library of the Royal Botanic Garden, Edinburgh; Dr Christine Carrico of the American Society of Pharmacology and Experimental Therapeutics for the photograph of Professor Raymond Ahlquist; Barlow Moor Books for obtaining a copy of Chen and Schmidt's Ephedrine and related substances; and my secretary, May Gibb.

\section{REFERENCES}

I Chen KK, Schmidt CF. Ephedrine and related substances. Baltimore: Williams and Wilkins Company; 1930. p. 4-6, 84-5.

2 Hagerty MJ, Woo M. Ephedra: ancient Chinese records. Flora Sinensis Ser B 1924; 24:I-30.

3 Scheindlin S. Ephedra: once a boon, now a bane. Mol Interv 2003 3:358-60. doi: $10.1124 / \mathrm{mi} .3 .7 .358$

4 Hyam R, Pankhurst R. Plants and their names: a concise dictionary Oxford: Oxford University Press; 1995. p. 173-4.

5 Anon. Begrüßung von Professor Dr.W. N. Nagai. Ber Dtsch Chem Ges 1927; 60:167-75.

6 Bruneton J. Pharmacognosy, phytochemistry, medicinal plants. Paris: Lavoisier; 1995. p. 7| I-4.

7 Merck E. Bericht über das Jahr 1894. Darmstadt: E Merck; 1894.

8 Miura K. Vorläufige Mitteilung über Ephedrin, ein neues Mydriaticum. Berl Klin Wochenschr 1887; 24:907-II.

9 Amatsu H, Kubota S. Über die pharmakologische Wirkung des Ephedrins und Mydriatins. Kyoto Igaka Zassi 1913; 10:301-9.

10 Barger G, Dale HH. Chemical structure and sympathomimetic action of amines.J Physiol 1910; 41:19-59.

II Chen KK, Schmidt CF. The action of ephedrine the active principle of the Chinese drug Ma Huang.J Pharmacol Exper Therapeut 1924; 24:339-57.

12 Miller TG. Ephedrine: its use in the treatment of vascular hypotension and bronchial asthma. Ann Clin Med 1926; 4:713-21.

13 Ahlquist RP. A study of the adrenotropic receptors. Am J Physiol 1948; 153:586-600.
14 Von Euler US. A specific sympathomimetic ergone in adrenergic nerve fibres (sympathin) and its relations to adrenaline and noradrenaline. Acta Physiol Scand 1946; 12:73-97. doi: I0.II II/j.1748-1716.1946. tb00368.x

15 Von Euler US. Noradrenaline. Springfield, Illinois: Charles CThomas; 1956. p. I-20.

16 Dollery C, editor. Therapeutic drugs. Vol. I. Edinburgh: Churchill Livingstone; 1991. p. E26-E29.

17 McCLeave DJ, Phillips PJ, Vedig AE. Compartmental shift of potassium - a result of sympathomimetic overdose. Aust N Z J Med 1978; 8: 180-3.

18 Van Mieghem W, Stevens E, Cosemans J. Ephedrine-induced cardiopathy. Br Med J 1978; I:816. doi:10.1 I36/bmj.I.6II6.816

19 Roxanas MG, Spalding J. Ephedrine abuse psychosis. Med J Aust 1977; 2:639-40

20 Konzett $\mathrm{H}$. Neue broncholytisch hochwirksame Körper der Adrenalinreibe. Arch Exp Path Pharm 1940; 197:27-40. doi:I0.1007/ BF0I936304

21 Hartley D, Jack D, Luntz $L$ et al. New class of selective stimulants of beta-adrenergic receptors. Nature 1968; 219:86I-2. doi: $10.1038 / 21986 / \mathrm{a} 0$

22 Sneader W. Drug discovery: the evolution of modern medicines. Chichester: John Wiley; 1985. p. $98-105$.

23 Maradona DA, Arcucci D, Cherquis Bialo E. El Diego: Diego Armando Maradona. London:Yellow Jersey Press; 2004.

24 Cooper P. Poisoning by drugs and chemicals. 3rd ed. London: Alchemist Publications; 1974. p. 95.

25 Rasmussen N. On speed: the many lives of amphetamine. New York: New York University Press; 2008. 